\title{
Enzymatic and immunochemical determination of plasminogen and plasmin in different physiological and pathological states
}

\author{
P. M. MANNUCCI, R. STABILINI, R. BRAGOTTI, BIANCA MARASINI, AND \\ A. AGOSTONI
}

From the Second Institute of Medical Pathology and Haemophilia Centre, University of Milan, Italy ${ }^{1}$

SYNOPSIS Plasminogen and plasmin have been determined in the same plasma samples in normal subjects and in various physiological and pathological conditions (pregnancy, liver cirrhosis, untreated cancer, and myocardial infarction during treatment with streptokinase) by means of two different methods. These were an enzymatic assay and a new immunochemical assay based on radial immunodiffusion employing cellulose acetate strips.

A significant correlation was found in normal subjects. However, in the other conditions marked discrepancies were observed in the results by the two methods. These findings might be related to variations in the functional activity of plasminogen and plasmin in disease.

Human plasmin and its proenzyme plasminogen can be estimated by a variety of techniques. Methods based on the observation of clot lysis are simple but relatively insensitive, whereas enzymatic assays are influenced by the levels of fibrinolysis inhibitors. In the past few years the availability of specific antisera has favoured the development of immunochemical methods, such as that of Ganrot and Niléhn (1968) which employs electrophoresis in agarose gel containing the specific antibodies. Moreover, a radioimmune assay for human plasminogen and/or plasmin has been recently devised with antibodies produced in the rabbit using as antigen highly purified human plasminogen (Rabiner, Goldfine, Hart, Summaria, and Rollins, 1969). These methods measure both plasminogen and plasmin, and are not affected by the inhibitors of plasmin or plasminogen activation.

The present study describes a new technique for the immunoassay of plasminogen and/or plasmin, based on radial immunodiffusion employing cellulose acetate strips. The levels obtained by this method have been compared with those determined by an enzymatic assay in normal subjects and in different physiological and pathological states such as preg-

Received for publication 21 July 1970.

${ }^{1}$ Postal address: Centro per lo Studio e la Terapia dell'Emofilia e delle Malattie Emorragiche, Pad. Beretta Est Via F. Sforza, 35, 20122, Milano, Italy. nancy, cancer, liver cirrhosis, and myocardial infarction during and after treatment with streptokinase.

\section{Material and Methods}

The investigation was carried out on 28 normal males (aged from 18 to 31 years) and 25 normal women (aged from 21 to 34 years) not receiving oral contraception; 29 normal women in the third trimester of pregnancy; 29 patients with decompensated liver cirrhosis documented by physical examination and laboratory findings; 28 patients with untreated cancer at different sites; and 12 patients with myocardial infarction under treatment with streptokinase. The latter was administered by continuous intravenous infusion according to a standard dosage scheme in which a starting dose of $250,000 \mathrm{U}$ in 20 minutes was followed by $100,000 \mathrm{U}$ hourly for 12 hours. Four plasma samples were examined at intervals, starting before the beginning of the infusion and then after four, 12, and 24 hours.

\section{PLASMA}

All blood samples were collected by venepuncture and delivered into plastic tubes containing 1 part of $3.8 \%$ sodium citrate to 9 parts of blood. Plasma was separated immediately by centrifugation at $2,000 \mathrm{~g}$ and stored in plastic tubes at $-20^{\circ} \mathrm{C}$. 
SERUM

Serum was separated from the blood two hours after clotting and stored at $-20^{\circ} \mathrm{C}$ until examined.

\section{ANTISERUM}

Antiserum to plasminogen/plasmin (Behringwerke, Marburg-Lahn, Germany) is prepared by immunizing rabbits with a purified preparation of plasminogen, the latter being obtained from human plasma Cohn fraction III, followed by chromatography on diethylaminoethyl cellulose (DEAE) Sephadex A 50. The antiserum specificity for human plasminogen and plasmin was established by immunoelectrophoresis. A single precipitation line developed when both human normal plasma and purified plasminogen were tested against the antiserum. These gave also a reaction of identity with immunodiffusion on agar gel.

\section{PURIFIED PLASMINOGEN}

Purified plasminogen preparations (Plasminogen, grade A, AB Kabi, Stockholm, Sweden) when tested failed to show a consistent uniformity of specific activity from batch to batch and within the same batch. So the values were expressed as percentages using a saline dilution curve from 40 pooled normal plasmas.

\section{ENZYMATIC DETERMINATION OF PLASMINOGEN/ PLASMIN}

This was carried out by a modification of the caseinolytic assay of Remmert and Cohen (1949). The results were expressed as the $60-\mathrm{min}$ increase in adsorbance at $276 \mu \mathrm{m}$ of the supernatant after precipitation of the proteins with trichloroacetic acid. Optical density readings were converted to percentage of average pooled normal plasma from the saline dilution curve prepared as above.

\section{IMMUNOCHEMICAL DETERMINATION OF PLASMINOGEN/PLASMIN}

The principle of simple radial immunodiffusion according to Mancini, Carbonara, and Heremans
(1965) was employed with the modifications suggested by Vergani, Stabilini, and Agostoni (1967). Strips of cellulose acetate (Schleicher and Schüll, Dassel/Kr., Germany) were used as carrier medium. The strips were stretched on a bridge in a moist Perspex chamber, and then uniformly soaked with $1 \mathrm{ml}$ antiserum, diluted $1 / 15$ with veronal buffer, $p H$ 8.6. Plasma or serum samples were applied and run undiluted and at a 1/2 dilution prepared using a $1 \mu$ l disposable micropipette (Microcaps, Drummond Scientific Co., Broomall, Pa, USA). One drop $(1 \mu l)$ of each sample was applied to the strip, and 50 different samples could be examined on a single strip.

Immunodiffusion was carried out using mineral oil (white oil 120, Manchester Oil Refinery, Great Britain) for 48 hours. The strip was then placed into a detergent solution (Teepol, Hopkin and Williams, Chadwell Heath, Great Britain) to wash off any trace of oil and then transferred for five minutes into a solution of $1 \%$ Haemosol (Meinicke and Co., Baltimore, USA) to remove unprecipitated proteins. The strip was then stained with amido black.

The diameters of the precipitate rings were directly measured with a Vernier gauge or a calibrated hand magnifying glass. Single values were expressed as percentages from the calibration curve.

\section{Results}

\section{IMMUNOCHEMICAL ASSAY PROCEDURE}

The precipitation rings were of adequate size and sharply outlined (Fig. 1). A linear relationship between the antigen concentration and the areas of precipitation was seen at the end of the diffusion. The diffusion was complete after 48 hours when the concentration of the antigen was in the range from 20 to $100 \%$ of normal. All the test samples were estimated when the results fell on the linear part of the calibration curve; with higher values, the relationship could not be extrapolated and samples had to be appropriately diluted.

This method can also be used with serum samples and these too show a linear relationship between

Fig. 1 Appearance of plasminogen/plasmin precipitin rings after immunodiffusion on cellulose strip (staining with amido black). 


\begin{tabular}{|c|c|c|c|c|c|}
\hline \multirow[t]{3}{*}{ Method } & \multicolumn{5}{|c|}{ Number of Samples } \\
\hline & Normals & Pregnancy & Cirrhosis & $\begin{array}{l}\text { Untreated } \\
\text { Cancer }\end{array}$ & $\begin{array}{l}\text { Myocardial Infarc- } \\
\text { tion under Treatment } \\
\text { with Streptokinase }\end{array}$ \\
\hline & 53 & 32 & 29 & 28 & 36 \\
\hline $\begin{array}{l}\text { Enzymatic } \\
\text { Immunochemical } \\
\text { Correlation coefficient between } \\
\text { the two methods }\end{array}$ & $\begin{array}{l}99.8 \pm 20.7 \\
100.6 \pm 10.4 \\
r=0.29^{3}\end{array}$ & $\begin{array}{l}129 \cdot 1 \pm 24 \cdot 9^{2} \\
135 \cdot 9 \pm 21 \cdot 5^{2} \\
r=0.27\end{array}$ & $\begin{array}{l}76.6 \pm 29.8^{2} \\
59.2 \pm 18.1^{2} \\
r=0.71^{4}\end{array}$ & $\begin{array}{l}140.9 \pm 55 \cdot 2^{2} \\
88 \cdot 8 \pm 17 \cdot 5^{2} \\
r=0.50^{4}\end{array}$ & $\begin{array}{l}21 \cdot 6 \pm 19 \cdot 1^{2} \\
70.6 \pm 23 \cdot 9^{2} \\
r=0.14\end{array}$ \\
\hline
\end{tabular}

Table I Plasminogen/plasmin levels (mean $\pm S D$ ) obtained by enzymatic and immunochemical methods in normal subjects, in pregnant women, and in patients with different pathological conditions 1

${ }^{2}$ Values expressed as percentage of a pool of 40 normal subjects. ${ }^{2} \mathrm{P}$ (versus normal) $<0.001$. ${ }^{3} \mathrm{P}(\mathrm{r}=0)<0.05$. ${ }^{4} \mathrm{P}(\mathrm{r}=0)<0.001$.

the concentration of the antigen and the area of the precipitation rings. However, since in the commonest clinical indications for the estimation of plasminogen/ plasmin, such as the 'defibrination' syndromes and during thrombolytic therapy, tests are usually carried out using citrated plasma, it was found more convenient to standardize the present method using plasma samples.

RELATIONSHIP BETWEEN IMMUNOCHEMICAL AND ENZYMATIC DETERMINATIONS

The plasminogen and plasmin concentration was determined immunologically and as caseinolytic activity in the same plasma samples from 53 normal

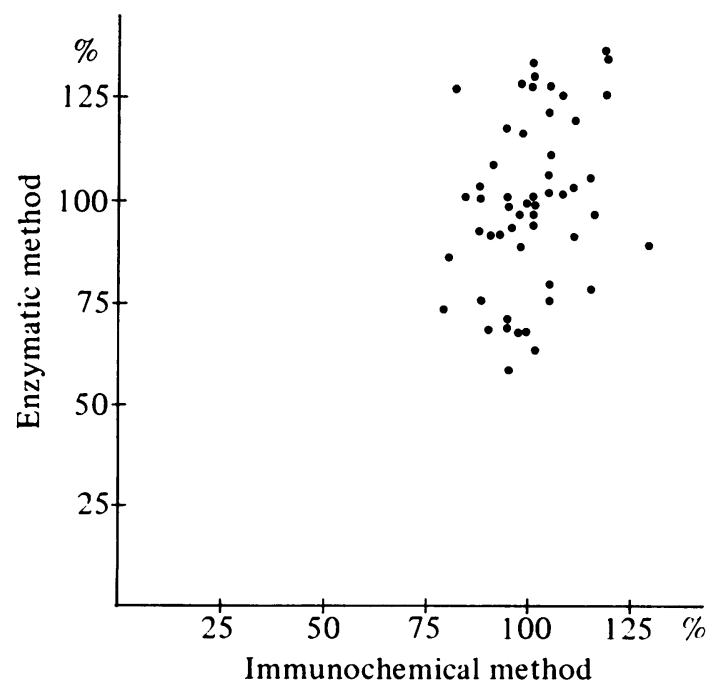

Fig. 2 The relationship of the enzymatic and immunochemical methods in 53 normal subjects $(r=0 \cdot 29$; $\mathbf{P}<0.05)$. individuals of both sexes. The mean value for the immunochemical method was $100.4 \pm 10.4 \%$, which was not significantly different from that obtained with the enzymatic method $(99 \cdot 8 \pm 20 \cdot 7)$ (Table I). No difference was found between males and females for both methods.

The two methods showed a slight correlation $(\mathrm{r}=0.29 ; \mathrm{P}<0.05)$ (Fig. 2).

The same plasma sample was determined on 20 different occasions with both the immunochemical and the enzymatic methods. The values varied from 97 to $114 \%$ for the immunochemical method (mean 105.7; SD 4.3 ) and from 81 to $127 \%$ for the enzymatic method (mean 99.7; SD 13.8). Thus the

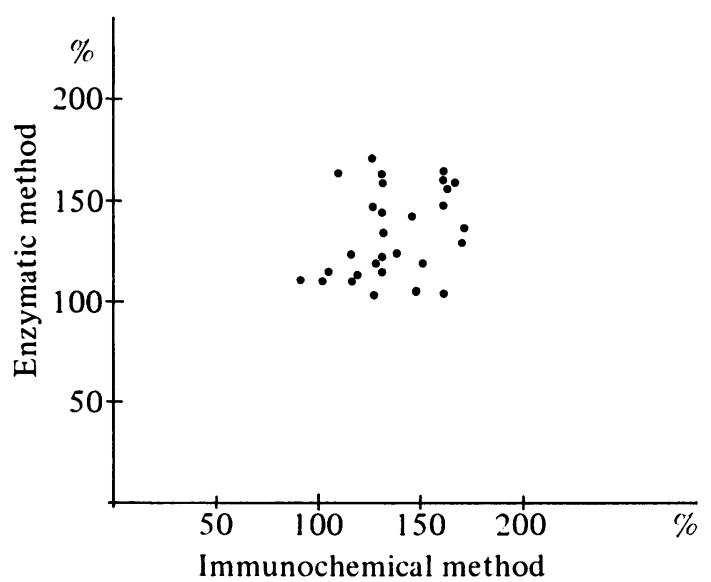

Fig. 3 The relationship of the enzymatic and immunochemical methods in 29 pregnant women $(r=0 \cdot 27$; not significant). 
variability was distinctly higher for the enzymatic (variation coefficient $13.8 \%$ ) than for the immunochemical method (variation coefficient $4 \cdot 1 \%$ ).

\section{PREGNANT WOMEN}

Twenty-nine women in the third trimester of pregnancy were investigated. The mean values were

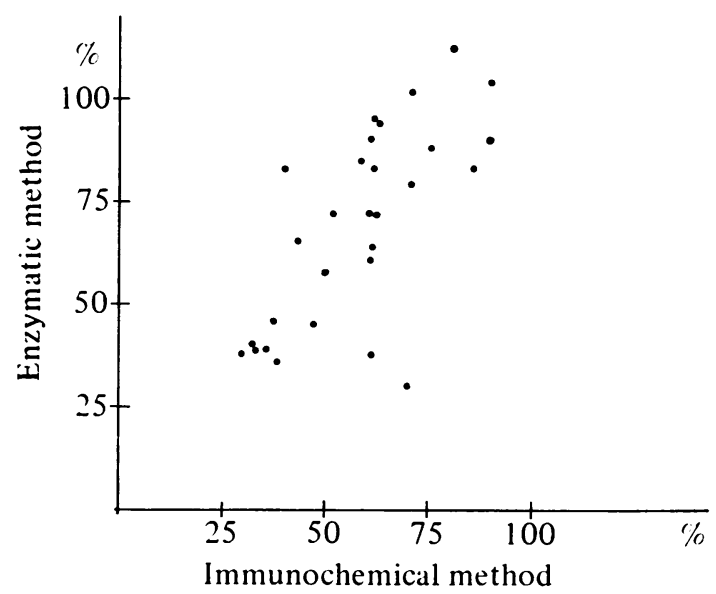

Fig. 4 The relationship of the enzymatic and immunochemical methods in 29 patients with liver cirrhosis $(r=0.71 ; \mathrm{P}<0.001)$.

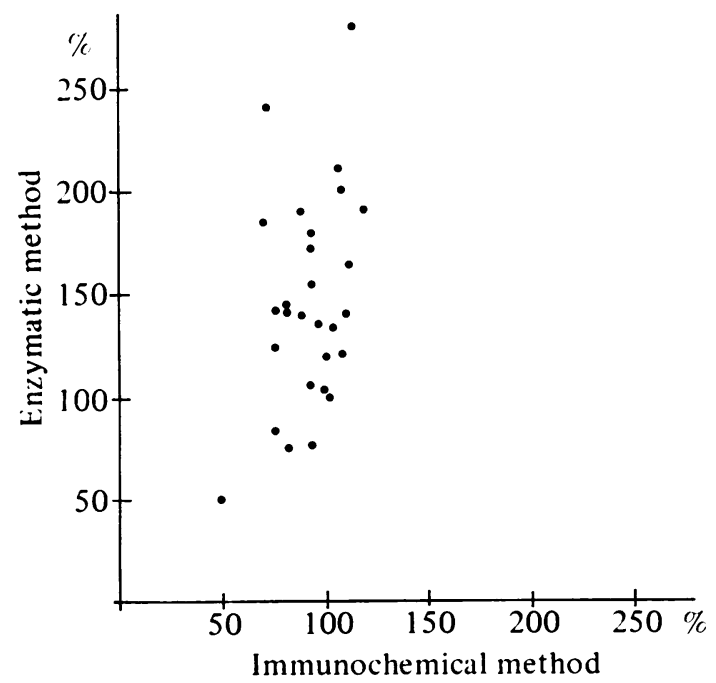

Fig. 5 The relationship of the enzymatic and immunochemical methods in 28 patients with untreated cancer $(r=0.50 ; \mathrm{P}<0.001)$. markedly increased for both methods and differences from normal were highly significant (Table I). The two methods were not significantly correlated $(r=0.27)$ (Fig. 3).

\section{LIVER CIRRHOSIS}

In patients with liver cirrhosis plasminogen/plasmin, assayed on the same plasma samples with both the immunochemical and enzymatic methods, was decreased and differences from normals were highly significant $(P<0.001)$ (Table I). However, the values obtained with the enzymatic method were higher than those obtained with the immunochemical method $(\mathrm{P}<0.001)$. The correlation coefficient between the enzymatic and immunochemical values was highly significant $(r=0.71)$ (Fig. 4).

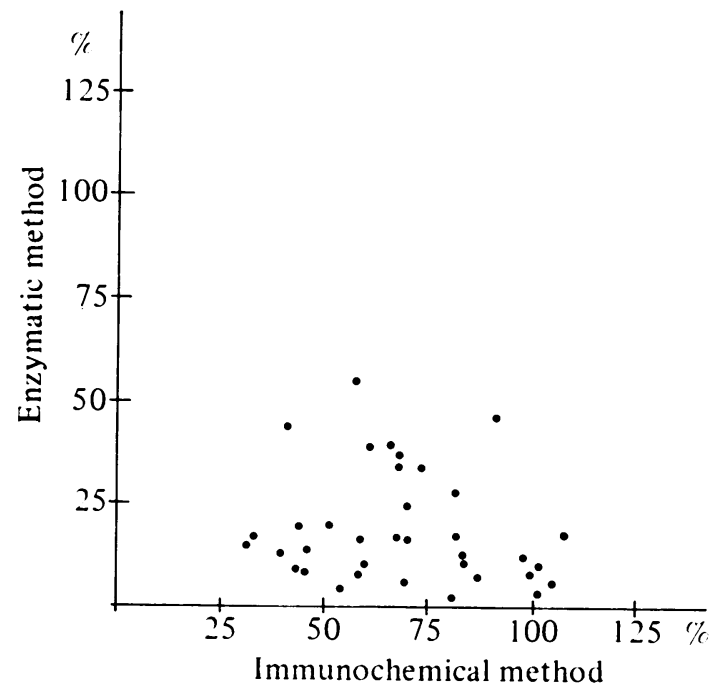

Fig. 6 The relationship between the enzymatic and immunochemical methods in 36 samples from 12 patients with myocardial infarction under treatment with streptokinase $(r=0 \cdot 14 ; N S)$.

\section{CANCER}

In the patients with advanced untreated cancer, the enzymatic assay gave higher values than the immunochemical assay (Table I). Differences from normals were highly significant with both the assays $(P<$ 0.001) which were positively correlated with each other (Fig. 5). No apparent relationship was demonstrated between the observed variations and the types of the tumours.

MYOCARDIAL INFARCTION TREATED WITH STREPTOKINASE

The methods were carried out on the same plasma 
samples obtained from 12 patients with acute myocardial infarction treated for 12 hours with a standard dosage scheme of streptokinase.

The 12 basal samples were not sufficiently numerous to allow a statistical analysis: however, the enzymatic method tended to give higher values than the immunochemical method. The values of the 36 samples processed during and after treatment were significantly decreased with both methods (Table I). However, the enzymatic method yielded much lower values and showed no correlation with the immunochemical method ( $r=0 \cdot 14)$ (Fig. 6).

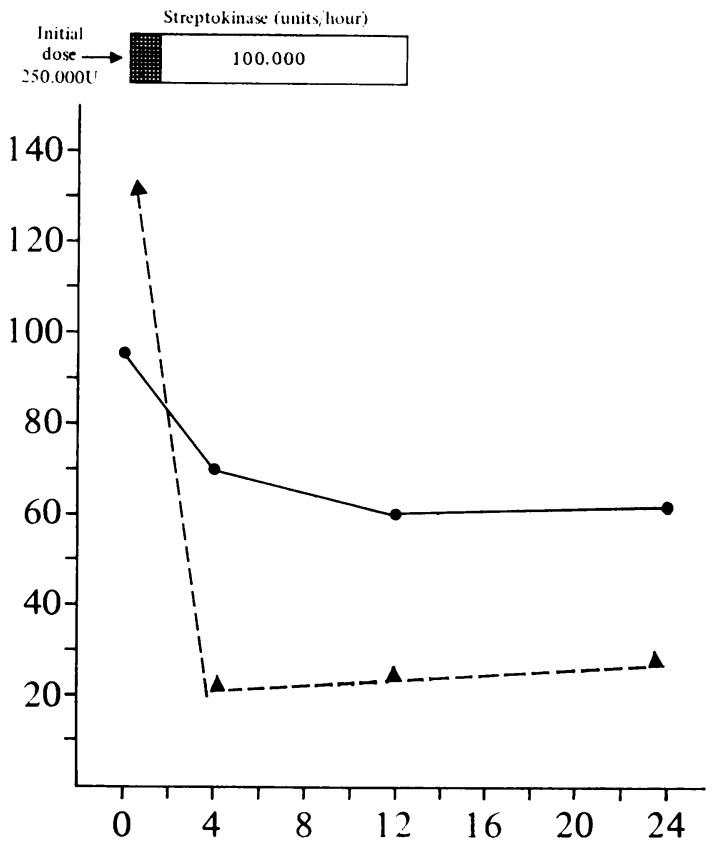

Fig. 7 The behaviour of plasminogen/plasmin determined by the enzymatic and immunochemical methods in seven patients with myocardial infarction during treatment with streptokinase ( $\Delta$ enzymatic methods; 1 immunochemical methods).

On the whole, enzymatic values were found to fall more rapidly and markedly after treatment with streptokinase (Fig. 7).

\section{Discussion}

The method described in the present study for immunochemical determination of plasminogen and/or plasmin is relatively simple and reproducible. The technique of radial immunodiffusion on cellulose acetate allows the use of small amounts of antiserum and the measurement of several samples on the same strip. Additional advantages are the uniformity of the supporting medium and the sharp definition of the precipitation rings which facilitates measurement.

Both plasminogen and plasmin react with the antiserum used in the present study, so that these activities cannot be determined separately. Moreover immunodiffusion is complete for $\mathbf{4 8}$ hours, thereby limiting its clinical use in situations of emergency. However, some of these unfavourable characteristics are shared by the other clot lysis, enzymatic, and immunochemical methods currently used.

The determination carried out in normal subjects with the immunological and enzymatic methods showed a weakly positive correlation. This is in agreement with previous observations of Ganrot and Niléhn (1968) and of Rabiner et al (1969), who related their findings to the influence exerted on the enzymatic assay by the inhibitors of fibrinolysis uncompletely inactivated by acidification.

The observation of a strong correlation found in the present study between the results of the two assays in the patients with liver cirrhosis seems to substantiate this explanation. Inhibitors of fibrinolysis which are known to be markedly decreased in liver failure (O'Connell, Grossi, and Rousselot, 1964) might reduce their influence on the enzymatic assay, thereby allowing a high correlation between the two assays.

It is, however, difficult on these grounds to explain the findings observed in the last trimester of pregnancy where both the methods yielded increased values, and in patients with untreated cancer where the enzymatic method yielded increased levels but the immunological method gave low concentrations. High to low levels of fibrinolysis inhibitors have been reported by a number of investigators in these conditions (Biezenski, 1958; Philips and Skrodelis, 1958; Brakman and Astrup, 1963; Pechet, 1965; Hilden, Amris, and Starup, 1967; Lauritsen, 1969), therefore it is difficult to establish whether the inhibitors might possibly account for the discrepancies between the enzymatic and immunochemical methods.

In these patients with myocardial infarction undergoing treatment with streptokinase who were examined at intervals during and after treatment up to 24 hours, the immunochemical method gave a more gradual and less marked decrease than the enzymatic method. The differences cannot be simply related to the property of the former technique of measuring plasminogen plus plasmin, because this also applies to the enzymatic method.

A possible explanation is that the complex formed between plasmin and $\alpha_{2}$-macroglobulin when the plasminogen is activated to plasmin during intra- 
venous infusion of streptokinase (Niléhn and Ganrot, 1967) retains some antigenic determinants common to both plasminogen and plasmin, while losing its enzymatic properties.

The discrepancies observed in the present study between the enzymatic and immunochemical method in various physiological and pathological conditions suggest that further clinical investigations using both the methods in various clinical states might be a useful way of measuring the relative changes in plasminogen/plasmin levels in the blood.

\section{References}

Biezenski, J. J. (1960). Antifibrinolytic activity in normal pregnancy. J. clin. Path., 13, 220-223.

Brakman, P., and Astrup, T. (1963). Selective inhibition in human pregnancy blood of urokinase induced fibrinolysis. Scand. $J$. clin. Lab. Invest., 15, 603-609.

Ganrot, P. O., and Niléhn, J. E. (1968). Immunochemical determination of human plasminogen. Clin. chim. Acta, 22, 335-340.

Hilden, M., Amris, C. J., and Starup, J. (1967). The haemostatic mechanism in oral contraception. Acta obstet. gynec. scand., 46, 562-571.

Lauritsen, O. S. (1969). The fibrinolytic enzyme system of human blood plasma in pregnancy. Scand. J. clin. Lab. Invest., 23, 191-196.

Mancini, G., Carbonara, A. O., and Heremans, J. F. (1965). Immunochemical quantitation of antigens by single radial immunodiffusion. Immunochemistry, 2, 235-254.

Niléhn, J. E., and Ganrot, P. O. (1967). Plasmin, plasmin inhibitors and degradation products of fibrinogen in human serum during and after an intravenous infusion of streptokinase. Scand. $J$. clin. Lab. Invest., 20, 113-121.

O'Connell, R. A., Grossi, C. E., and Rousselot, L. M (1964) Role of inhibitors of fibrinolysis in hepatic cirrhosis. Lancet, 2, 990-991.

Pechet, L. (1965). Fibrinolysis. New Engl. J. Med., 273, 966-973.

Phillips, L. L., and Skrodelis, V. (1958). The fibrinolytic enzyme system in normal, hemorrhagic and disease states. J. clin., Invest., 37, 965-973.

Rabiner, S. F., Goldfine, I. D., Hart, A., Summaria, L., and Robbins K. C. (1969). Radioimmunoassay of human plasminogen and plasmin. J. Lab. clin. Med., 74, 265-273.

Remmert, L. F., and Cohen, P. P. (1949). Partial purification and properties of a proteolytic enzyme of human serum. J. biol. Chem., 181, 431-448.

Vergani, C., Stabilini, R., and Agostoni, A. (1967). Quantitative determination of serum immunoglobulins by single radial immunodiffusion on cellulose acetate. Immunochemistry, 4, 233-237.

\section{Reports and Bulletins prepared by the Association of Clinical Biochemists}

The following reports and bulletins are published by the Association of Clinical Biochemists. They may be obtained from The Administrative Office, Association of Clinical Biochemists, 7 Warwick Court, Holborn, London, WC1 R 5DP. The prices include postage, but airmail will be charged extra. Overseas readers should remit by British Postal or Money Order. If this is not possible the equivalent of $50 \mathrm{p}$ is the minimum amount that can be accepted.

\section{SCIENTIFIC REPORTS}

3 Automatic Dispensing Pipettes. An assessment of 35 commercial instruments 1967 P. M. G. BROUGHTON, A. H. GOWENLOCK, G. M. WIDDOWSON, and K. A. AHLQUIST $85 \mathrm{p}(\$ 2)$

4 An Evaluation of 5 Commercial Flame Photometers suitable for the Simultaneous Determination of Sodium and Potassium March 1970 P. M. G. BROUGHTON and J. B. DAWSON $85 \mathrm{p}(\$ 2)$

\section{TECHNICAL BULLETINS}

9 Determination of Urea by AutoAnalyzer November

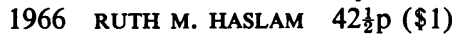

10 Filter Fluorimeters. A comparative list of 14 instruments March 1967 HANNELORE BRAUNSBERG (Reissued in response to demand. Text still valuable, list now out of date) $42 \frac{1}{2} \mathrm{p}(\$ 1)$

11 Determination of Serum Albumin by AutoAnalyzer using Bromocresol Green October 1967 B. E. NORTHAM and G. M. WIDDOwSON $42 \frac{1}{2} \mathrm{p}(\$ 1)$

13 An Assessment of the Technicon Type II Sampler Unit March 1968 B. C. GRAY AND G. K. MCGOWAN $42 \frac{1}{2} \mathrm{p}(\$ 1)$
14 Atomic Absorption Spectroscopy. An outline of its principles and a guide to the selection of instruments May 1968 J. B. DAWSON and P. M. G. BROUGHTON $42 \frac{1}{2} \mathrm{p}(\$ 1)$

15 A Guide to Automatic Pipettes (2nd edition) June

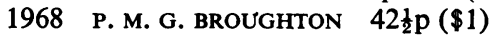

16 A Guide to Automation in Clinical Chemistry May

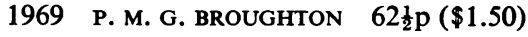

17 Flame Photometers (2nd edition) 1969 P. WILDING $62 \frac{1}{2} \mathrm{p}(\$ 1.50)$

18 Control Solutions for Clinical Biochemistry (4th

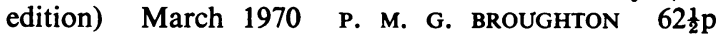
$(\$ 1.50)$

19 Spectrophotometers. A comparative list of low-priced instruments readily available in Britain May 1970 C. E. WILDE and P. SEWELL $62 \frac{1}{2} \mathrm{p}(\$ 1.50)$

20 Quantities and Units in Clinical Biochemistry June 1970 P. M. G. BROUGHTON $62 \frac{1}{2} \mathrm{p}(\$ 1.50)$ More than 30 copies in units of 10 at 20 p

21 Filter Fluorimeters: A comparative list of 18 instruments September 1970 H. BRAUNSBERG and $s$. $s$. BROWN $62 \frac{1}{2} \mathrm{p}(\$ 1.50)$ 